\title{
The Cost of Mating: Influences of Life History Traits and Mating Strategies on Lifespan in Two Closely Related Yponomeuta Species
}

\author{
A. C. Bakker, J. Campos Louçã, P. Roessingh, and S. B. J. Menken \\ Institute for Biodiversity and Ecosystem Dynamics, University of Amsterdam, P.O. Box 94240, 1090 GE Amsterdam, The Netherlands \\ Correspondence should be addressed to P. Roessingh, roessingh@uva.nl
}

Received 23 December 2010; Revised 21 February 2011; Accepted 18 May 2011

Academic Editor: Marie Herberstein

Copyright () 2011 A. C. Bakker et al. This is an open access article distributed under the Creative Commons Attribution License, which permits unrestricted use, distribution, and reproduction in any medium, provided the original work is properly cited.

\begin{abstract}
Theory predicts that in monandrous butterfly species males should not invest in a long lifespan because receptive females quickly disappear from the mating population. In polyandrous species, however, it pays for males to invest in longevity, which increases the number of mating opportunities and thus reproductive fitness. We tested an extension of this idea and compared male and female lifespan of two closely related Yponomeuta species with different degree of polyandry. Our results confirmed the theoretical prediction that male lifespan is fine-tuned to female receptive lifespan; once-mated males and females of both polyandrous species had an equal lifespan. However, the degree of polyandry was not reflected in male relative to female lifespan. The observed similar female and male lifespan could largely be attributed to a dramatic reduction of female lifespan after mating.
\end{abstract}

\section{Introduction}

Multiple mating can have both positive and negative effects on female fitness [1-5]. Together these benefits and costs determine the optimal mating rate of a female. Knowledge of the species-specific advantages and disadvantages of monandry (females mate only once) and polyandry (females mate more than once) is important for understanding the adaptive significance of mating systems. Negative effects of multiple mating include an increase of energy and time spent on mating, as well as the concomitant increased vulnerability to predation, sexual diseases, parasites, and pathogens [6]. Furthermore, an excess of sperm can have a negative effect on both egg production rate (and thus female fecundity) and fertility ([7], and references therein). In addition, in polyandrous species, mating may reduce female lifespan as a consequence of male manipulation [6-9]. Manipulation comprises both the transfer of toxic compounds, such as those found in Drosophila fruit flies [10], the bruchid Acanthoscelides obtectus [11], or the nematode Caenorhabditis elegans [12], and physical damage, such as that brought about by bed bugs [13], the bruchid Callosobruchus maculatus [14], or the dung fly Sepsis cynipsea [15]. Considering these negative effects, it may seem surprising that multiple mating is the rule in insects at rates that are often much higher than required for fertilizing the total egg content of a female [7]. Therefore, there must also be positive effects associated with polyandry. These positive effects include compensation for mating with a genetically incompatible, inferior, or infertile male and an increase in genetic variability among the offspring ([16, 17], and references therein). Moreover, substances in the male ejaculate (nuptial gifts) can increase female lifespan $[18,19]$, female fecundity (see [20] for an overview), and offspring fitness $[21,22]$. Positive effects of the ejaculate act either directly, by providing extra resources for somatic maintenance of females ([18] and references therein $[19,23])$, or indirectly, by protecting the female against predators (e.g., the pyrrolizidine alkaloids transferred by male Utetheisa ornatrix [24]).

The mating strategy of a species and multiple mating in particular may influence certain life history traits such as lifespan. Wiklund et al. [25] suggested that in Lepidoptera different mating systems may select for different sex-specific mortality rates. In species where females mate multiple times, receptive females are continuously available, and males that allocate resources to increase their lifespan may 
directly increase their number of opportunities to mate and consequently their reproductive fitness. Wiklund et al. [25] showed that males of a polyandrous species indeed lived as long as their conspecific females while males of a monandrous species did not. Males of a monandrous species (under the condition of high synchrony in receptivity patterns among individual females) are expected to allocate resources to other traits that improve reproductive success, such as development rate, pheromone production, and flight muscles. Fast development leading to males emerging before females (protandry) is advantageous in precopulatory male competition, whereas male sex pheromones facilitate efficient signalling of partners (e.g., in species that form male leks [26]) flight muscles improve flight ability and thus the capability of pursuing and catching females (e.g., in Papilionidae: [27] and in Nymphalidae [28]).

Here we extend the hypothesis of Wiklund et al. [25] and hypothesize that the overall chances of males of encountering a receptive female should affect to which extent resources would be allocated to prolong male reproductive lifespan. If in a species many females mate only once and few more than once, it is expected that males invest in traits other than lifespan (assuming females are receptive around the same time). We therefore predict that the degree of polyandry will be reflected in the lifespan of males relative to females.

When testing this hypothesis, certain other life history traits and effects of mating need to be considered. First, in Lepidoptera, positive $[19,29-33]$, negative $[9,34]$, or no effects $[35,36]$ of mating on lifespan have been observed in either sex or in both sexes. Therefore, the effect of mating itself needs to be considered when investigating sex-specific longevity and relating it to male investment in lifespan. A second aspect that needs to be taken into account is the possible effect of body size. In many species, larger individuals tend to live longer than smaller ones, and females tend to be larger than males ([37] and references therein). Therefore, it may be expected that individuals that have developed from heavier pupae live longer, as they may allocate more resources to the prolongation of adult life. If indeed females are larger than males, this might cause (all else being equal) lifespan to be sex specific. The influence of mating itself and possible effects of body size on sex-specific lifespan were unfortunately not investigated by Wiklund et al. [25].

In this study we reevaluate the hypothesis proposed by Wiklund et al. [25] and specifically investigate if it holds for species with different degrees of polyandry. We used two closely related species from the genus Yponomeuta (Lepidoptera: Yponomeutidae). Yponomeuta cagnagellus (Hübner) and Y. padellus (L.) have synchronized female eclosion in the field and can remate until the end of their life (A. C. Bakker, unpublished data). Females of both species mate maximally once per day. Yponomeuta padellus females show synchronized sexual maturity (as indicated by female 'calling' behaviour) and have similar age at first mating in the laboratory $[38,39]$. Yponomeuta cagnagellus females also show synchronized sexual maturity [38] but the age of females mating for the first time can vary widely, and this may indicate that $Y$. cagnagellus females are choosy [39]. The two species are closely related $[40,41]$ and therefore very much alike in many of their life history traits and behaviour. They do however differ in lifespan, and although both are able to mate more than once, they display significant differences in female mating frequencies [39]. The average mating frequency of $Y$. cagnagellus females are $3.0 \pm 0.3$ times (mean \pm standard error). In the laboratory, they can mate up to 9 times. The average mating frequency of $Y$. padellus females is $2.0 \pm 0.2$, and a majority of females is mating only once [39]. We can therefore conclude that $Y$. cagnagellus females are highly polyandrous and Y. padellus females have a low degree of polyandry.

We ask four questions in this paper: (1) are male and female lifespans equal in polyandrous species as Wiklund et al. [25] predicts? (2) Can Wiklund's hypothesis be extended to cover sex-specific adjustment of lifespan related to the degree of polyandry of the species? (3) Does mating affect lifespan? (4) Is there a significant effect of pupal weight on lifespan?

\section{Materials and Methods}

In the summer of 2004, fifth instars of the monophagous $Y$. cagnagellus were collected in the Netherlands in Castricum $\left(52^{\circ} 32^{\prime} \mathrm{N}, 4^{\circ} 38^{\prime} \mathrm{E}\right)$, Amsterdam $\left(52^{\circ} 8^{\prime} \mathrm{N}, 4^{\circ} 29^{\prime} \mathrm{E}\right)$, and Overveen $\left(52^{\circ} 23^{\prime} \mathrm{N}, 4^{\circ} 34^{\prime} \mathrm{E}\right)$ from Euonymus europaeus (Celastraceae). Fifth instars of the oligophagous Y. padellus were collected in Leiden $\left(52^{\circ} 21^{\prime} \mathrm{N}, 4^{\circ} 56^{\prime} \mathrm{E}\right)$ from Crataegus monogyna (Rosaceae). They were reared as described below on leaves of their host plant. After eclosion, adult moths were placed under a net on their host plant and allowed to mate and lay eggs. Egg batches with first instars were kept outdoors under natural conditions. In the next spring, egg batches were opened and the first stadium larvae fed in Petri dishes $(10 \mathrm{~cm} \varnothing)$ with a maximum of 15 L5 larvae per dish on freshly picked leaves of Prunus spinosa (Rosaceae) for Y. padellus and E. europaeus for Y. cagnagellus, at $22^{\circ} \mathrm{C}, 60 \%$ R.H., and L17:D7 photoperiod until pupation. Pupae were weighed individually on an OHAUS Analytical Standard Scale $(d=0.0001 \mathrm{~g})$ microbalance (OHAUS, Viroflay, France) after their pupal skin had hardened. They were subsequently placed in individual glass vials $(8 \mathrm{~cm}$ high and $2 \mathrm{~cm} \varnothing$ ) that were closed with a cotton wool plug and stored in climate boxes at $20^{\circ} \mathrm{C}$ during the photophase and $18^{\circ} \mathrm{C}$ during the scothophase, $70-80 \%$ R.H, and L17:D7 photoperiod.

We used pupal weight as a proxy for body size to test for a correlation with longevity. For all individuals the number of days between weighing and eclosion was recorded. Pupae were weighed between 3 and 13 days prior to eclosion, with an average of $6.8 \pm 0.1$ days for $Y$. padellus and $8.0 \pm 0.2$ days for $Y$. cagnagellus. The weight of pupae diminishes every day until eclosion (weight loss amounts to $1.18 \pm 0.07 \%$ per day for Y. cagnagellus and $1.15 \pm 0.04 \%$ per day for Y. padellus). To correct for this confounding factor, we estimated the rate of weight loss in the controls of the two species using a regression of pupal weight against time to eclosion for males and females of both species and used these results to predict pupal weight of all insects at the time of eclosion. 
TABLE 1: ANOVA table of a GLM model to estimate the effects of sex, species, mating status, and the interaction of sex and species on pupal weight at the time of adult eclosion.

\begin{tabular}{lcccccc}
\hline Model terms & Degree of freedom & Deviance & Residual degree of freedom & Residual deviance & $F$ & $P$ \\
\hline Null model & & & 502 & 26345.9 & & \\
Sex & 1 & 6037.5 & 501 & 20308.4 & 207.6 & $0.0000^{* * *}$ \\
Species & 1 & 5806.3 & 500 & 14502.1 & 199.7 & $0.0000^{* * *}$ \\
Sex $*$ species & 1 & 16.5 & 498 & 14479.8 & 0.567 & 0.4517 \\
Mating status & 1 & 5.8 & 499 & 14496.3 & 0.199 & 0.6555 \\
\hline
\end{tabular}

$P<0.05, P<0.01,{ }^{* * *} P<0.001$.

These estimated weights were subsequently used as a covariate in the GLM analyses to evaluate the effect of pupal weight (as proxy for adult size) on lifespan. To minimize uncontrolled differences in weight loss due to variations in humidity, all experiments were conducted in the same room, and all treatments were run simultaneously.

After eclosion, moths were sexed and supplied once a week with a cube of 10\% honey-containing 1\% agar (w/v; type 1-D LEEO: Sphaero-Q, Leiden, The Netherlands). When the moths were sexually mature, that is, at 14-18 days after eclosion for $Y$. cagnagellus and 8-14 days for $Y$. padellus, individuals were randomly assigned to either the mated or the virgin (control) group. One female and one male were placed together in a Petri dish in the climate room at $20-21^{\circ} \mathrm{C}, 60-85 \%$ R.H., with a L17:D7 cycle (of which the photophase contained $1 \mathrm{~h}$ twilight at dawn, provided by a $40 \mathrm{~W}$ screened lamp). A red darkroom lamp (Philips PF712E, 15W) allowed us to observe the moths during the scothophase without disturbing them. The mated group was allowed to mate once. The females and males of the control group were treated similarly, except that they were placed individually in Petri dishes. Data were collected from 43 Y. cagnagellus mating pairs, and 49 unmated males and 51 unmated females served as controls. For Y. padellus, 54 mating pairs were analysed, and 55 unmated males and 59 unmated females were controls. After mating had ended, male and female moths were placed individually in glass vials and were provided with a piece of polystyrene which served as an oviposition substrate. They were kept in a climate box under the same conditions as when they were maturing and were continued to be fed once a week. Survival and oviposition were checked daily, with the exception of a few weekends where checks were made only once in 2 days.

2.1. Statistical Analysis. The effects of sex and species on pupal weight and a possible difference in pupal weight between treatment groups were investigated using a GLM model that included these factors and a gausian variance function.

To investigate the effects of species, sex, and mating status on lifespan, we used a GLM model with a quasipoisson variance function (appropriate for lifespan data that showed a clear poisson distribution with a tail towards long lifespan). Main effects for species, sex, and mating status were included, as well as the covariate pupal weight (corrected for weight loss since weighing as described above). To test for sexspecific lifespan, a sex ${ }^{*}$ species interaction term was included. To test the differential effects of mating, a sex* mating status and a species $*$ mating status terms were also included. All statistical tests were performed in $\mathrm{R}$ (version 2.9.1 [42]). Throughout the study, average values are presented together with their standard errors.

\section{Results}

3.1. Pupal Weight. Pupal weights of Y. padellus ranged from 17.6 to $48.5 \mathrm{mg}$ for females and from 17.8 to $39.2 \mathrm{mg}$ for males. In the heavier $Y$. cagnagellus, pupal weights ranged from 28.7 to $57.4 \mathrm{mg}$ for females and for males from 21.1 to $46.7 \mathrm{mg}$. A generalized linear model (Table 1) with estimated pupal weight at the day of eclosion as the dependent variable showed significant main effects of both sex and species, but no interaction effect between them, and no effect of treatment (mated or control). The correlations showed that $Y$. cagnagellus is significantly heavier than $Y$. padellus and that females of both species are heavier than males. The lack of a main effect of treatment (mating status) showed that our experimental groups did not systematically differ in weight (Figure 1).

3.2. Lifespan. The individual lifespan of $Y$. padellus ranged from 15 to 94 days for females $(n=113)$ and from 19 to 74 days for males $(n=109)$. In $Y$. cagnagellus female lifespan ranged from 17 to 146 days $(n=90)$ and for males from 22 to 115 days $(n=92)$. We used a generalized linear model to evaluate the influence of species, sex, mating status, and the covariate pupal weight on lifespan (Table 2). The model showed significant effects for all the factors as well as strong interaction effects (Figure 2, Table 2). Inspection of the coefficients for the main effects showed that Y. cagnagellus lived significantly longer than $Y$. padellus, that females lived longer than males, that mating reduced lifespan significantly, and that a higher pupal weight at eclosion increased lifespan. The presence of a significant interaction of sex and mating status revealed however that the effects of mating differed strongly between the sexes. Mating reduced lifespan in both sexes but significantly more in females than in males.

The interaction between sex and species on the other hand was not significant. While overall the lifespan of $Y$. cagnagellus was longer than that of $Y$. padellus and females 
TABLE 2: ANOVA table of a GLM model to estimate the effects of sex, species, mating status, the covariate pupal weight, and specific planned contrasts.

\begin{tabular}{|c|c|c|c|c|c|c|}
\hline Model term & Degree of freedom & Deviance & Residual degree of freedom & Residual deviance & $F$ & $P$ \\
\hline Null model & & & 502 & 5055.8 & & \\
\hline Species & 1 & 1381.3 & 500 & 3674.5 & 241.63 & $0.0000^{* * *}$ \\
\hline Sex & 1 & 274.0 & 501 & 3400.5 & 47.94 & $0.0000^{* * *}$ \\
\hline Mating status & 1 & 273.3 & 499 & 3127.2 & 47.81 & $0.0000^{* * *}$ \\
\hline Pupal weight & 1 & 31.9 & 498 & 3095.3 & 5.58 & $0.0185^{*}$ \\
\hline Sex $*$ species & 1 & 20.1 & 497 & 3075.2 & 3.52 & $0.0612^{\text {n.s. }}$ \\
\hline Sex $*$ mating status & 1 & 123.2 & 496 & 2952.0 & 21.55 & $0.0000^{* * *}$ \\
\hline Species $*$ mating status & 1 & 6.8 & 495 & 2945.2 & 1.19 & $0.2765^{\text {n.s. }}$ \\
\hline Sex $*$ Pupal weight & 1 & 46.7 & 494 & 2829.5 & 8.16 & $0.0046^{* *}$ \\
\hline
\end{tabular}

${ }^{*} P<0.05,{ }^{* *} P<0.01,{ }^{* * *} P<0.001$.

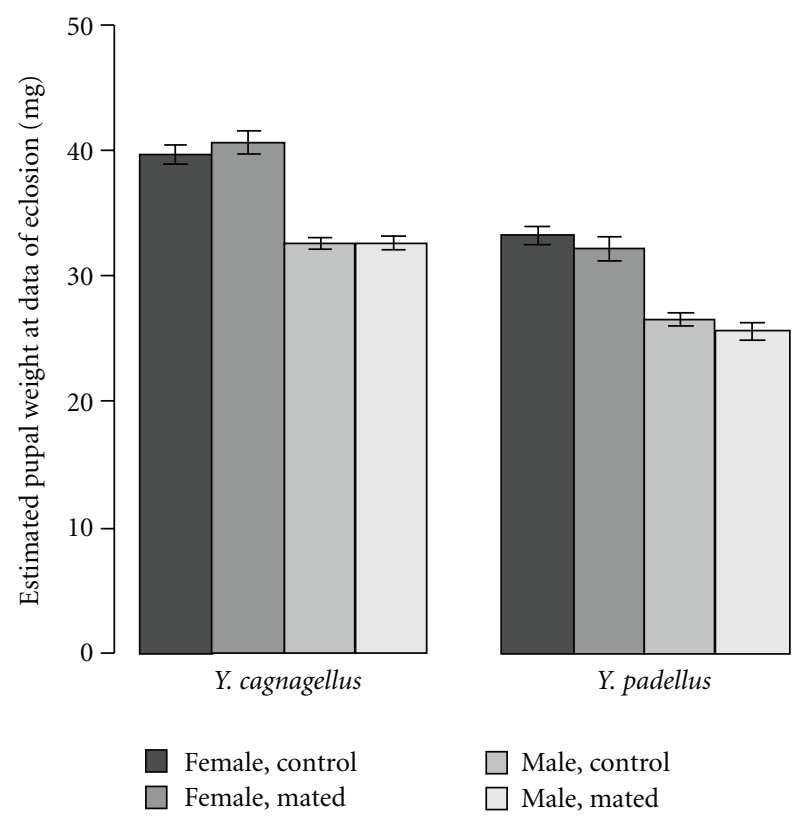

FIGURE 1: Estimated pupal weights (in $\mathrm{mg}$ ) at the day of eclosion as a function of species (Yponomeuta padellus or Yponomeuta cagnagellus), sex, and mating status (virgin control or once mated).

lived longer than males, there was no significant sex-specific lifespan difference between $Y$. padellus (the less polyandrous species) and $Y$. cagnagellus (the longer living and more polyandrous species).

A positive main effect of pupal weight on lifespan was found, but this correlation was also dependent on sex, and close examination of the coefficients showed that lifespan was significantly more positively influenced by pupal weight in males than in females.

All the interaction effects described above are also evident in the survival curves presented in Figure 3. The significant negative effect of mating on lifespan in the two species is clearly visible, resulting in equal lifespan for males and females. The interaction effect of mating status with species is represented by the relative large reduction of lifespan in $Y$. cagnagellus females after mating.

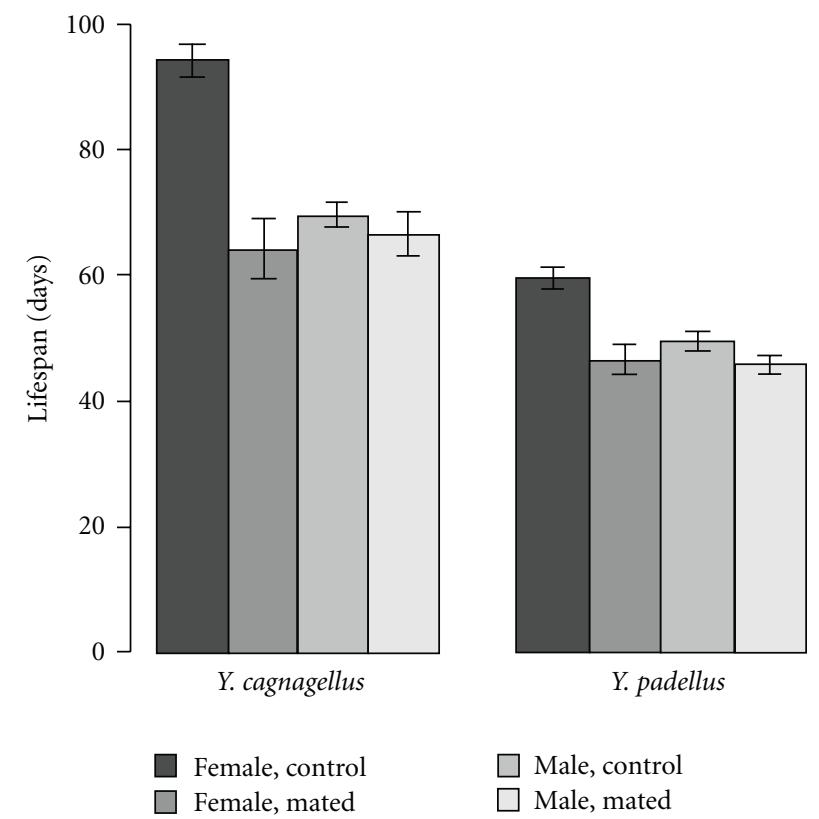

Figure 2: Lifespan (in days) as a function of species (Yponomeuta padellus or Yponomeuta cagnagellus), sex, and mating status (virgin control or once mated).

\section{Discussion}

4.1. Effect of Degree of Polyandry on Male Investment in Lifespan. We investigated sex-specific lifespan of two Yponomeuta species that differ in some life history traits and in degree of polyandry. We tested the hypothesis of Wiklund et al. [25] that males of polyandrous species invest in lifespan because this will lead to more matings and thus more offspring and higher fitness. We chose species with a different level of polyandry to test if Wiklund's original suggestion would hold even when the degree of polyandry is considered. Our results confirmed the theoretical prediction of polyandrous species having male lifespan close to female lifespan: once-mated males and once-mated females had an equal lifespan. The hypothesis of Wiklund et al. [25] implies that males of polyandrous species continue to live 


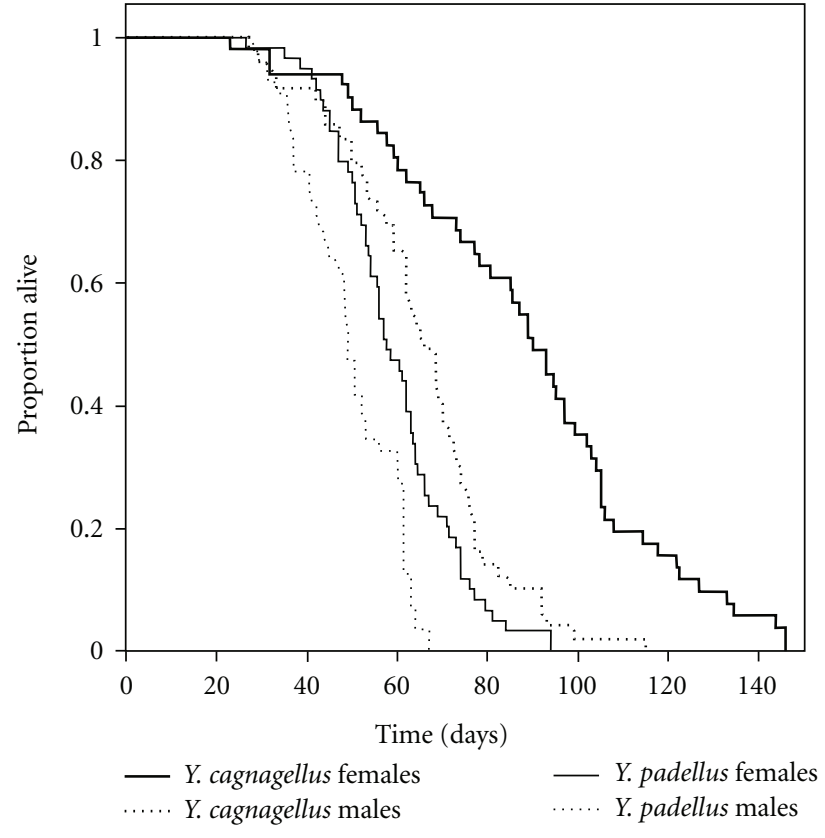

(a)

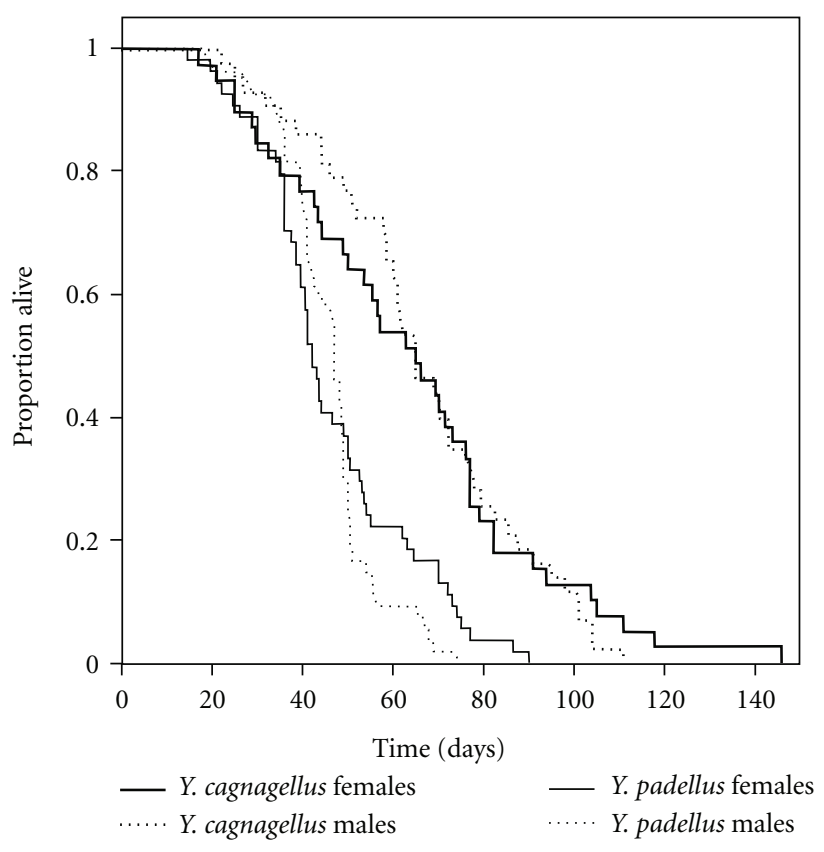

(b)

Figure 3: (a) Survival curves of virgin adult Yponomeuta padellus and Yponomeuta cagnagellus males and females. Day 0 is the day of eclosion. (b) Survival curves of mated adult Yponomeuta padellus and Yponomeuta cagnagellus males and females. Day 0 is the day of eclosion.

after the peak of female receptivity (at least under the condition that females receptivity is synchronous, as is the case in Yponomeuta) and thus live past the moment that most females have mated once. Indeed, our results showed that in both species males live long after the peak of female receptivity: males of both species live on average more than 45 days after eclosion, but $Y$. cagnagellus females are receptive at $14.6 \pm 1.2$ (mean $\pm \mathrm{SE}$ ) days and Y. padellus females at 4.9 \pm 0.6 days after eclosion [39].

We extended Wiklund's hypothesis to sex-specific lifespan differences between high and low polyandrous species and expected a larger investment in lifespan in Y. cagnagellus males; that is, we predicted a significant sex by species interaction on lifespan. This effect was not found (Table 2) and while both sex and species influence lifespan, the effects are similar in both species, and we were unable to find evidence for an increase in male investment in lifespan in the more polyandrous species.

4.2. Effects of Mating on Lifespan. In Lepidoptera mating can have both positive and negative effects on male and female lifespan (e.g., [9, 19, 29-34, 43]). One of our objectives was therefore to investigate if, and how, mating influenced lifespan in Y. padellus and Y. cagnagellus. In our experiment, a single mating event reduced lifespan of both species, but in particular that of females. Apparently, any advantageous effects of mating on female lifespan were outweighed by disadvantageous ones. This net negative effect on female lifespan might be a side effect (i.e., pleiotropic) of male traits that are beneficial in sperm competition; alternatively, males might deliberately harm females in order to stimulate a higher oviposition rate or to prevent females from remating (as is formulated in the adaptive harm hypothesis: $[6,44]$ ). There are few studies on Lepidoptera in which lifespan of mated females is compared with virgin female lifespan; in many studies only lifespan of single-mated females has been compared with that of multiple-mated ones. A comparable negative effect of mating on lifespan was found in Ostrinia nubilalis (Crambidae) [34] and in Colias eurytheme (Pieridae) [9].

While the above explanations picture the reduction in lifespan after mating as a cost of mating, other explanations cannot be excluded. The reduction in lifespan could in principle also be caused by a higher activity of females that were paired up (i.e., activity of females before mating, extensive walking or flying behaviour in search of a suitable oviposition site after mating). However, in our experimental setup, the moths are placed in Petri dishes and glass vials where they cannot easily spend resources on locomotion behaviour. Although we have not formally recorded behaviour, our daily observations showed that moths in all treatments stayed largely in one place (females call while being motionless and only move around if they do not want to mate), and we have no reason to believe that paired females were more active than virgin females.

Another explanation for the reduction of lifespan after mating could be a change in physiology (i.e., allocation of energy to eggs after fertilisation). Although this would still represent a cost of reproduction, it would not be a true cost of mating. The design of our experiment is however not suitable to address the difference between reproduction and mating. We used an artificial oviposition substrate, 
on which only 13 out of 90 Y. cagnagellus and 15 out of 113 Y. padellus females laid eggs (several unmated females also oviposited). But even in experiments in which oviposition is better facilitated and monitored, it is not easy to discriminate between hypotheses based on physiological changes and hypotheses based on harm or male manipulation. Regardless of the underlying cause for the effect of mating, we found a significant $\operatorname{sex} *$ mating status interaction. A single mating in Yponomeuta did reduce male lifespan significantly less than female lifespan even though males of both species transferred an ejaculate comprising some $15 \%$ of their body weight during a single mating [45]. Mating also had no effect on male lifespan in Danaus plexippus (Nymphalidae), which transfers an ejaculate that amounts up to $10 \%$ of its body mass [46, 47], nor in Callophrys xami (Lycaenidae), with an ejaculate of some $3 \%$ of its body mass [48]. However, under resource limitation (achieved by starving the larvae), multiple-mated males of C. xami lived shorter than virgin males [48]. We did not test whether resource limitation influences the effect of mating on lifespan. In our study, as in that of Oberhauser [47], and in the non-resource limiting experiment of Cordero [48], adult males were provided with a sugar or honey solution, and this may have enabled them to replenish some of their resources. On the other hand, as species differ in the allocation of larval and adult resources to reproduction and lifespan [49], it is conceivable that in Yponomeuta, resources for male lifespan cannot be allocated to reproduction. Another important difference with the studies of Oberhauser [47] and Cordero [48] is that males were mated multiple times, while in this study males were mated just once. This difference is important because the relationship between lifespan and number of matings could be nonlinear.

4.3. Influence of Pupal Weight on Lifespan. Most Lepidoptera acquire most, if not all, of their resources during larval life (so-called capital breeders [50]). These resources can in principle be allocated to prolong lifespan, enhance mate finding, or increase the number and quality of eggs or ejaculate, all of which might increase reproductive output. By measuring pupal weight, we have indirectly investigated the correlation between resources acquired during the larval stage and adult lifespan, and we expected to find a positive correlation between pupal weight and adult lifespan, a mechanism found across many species ([37] and references therein). Larval weight was indeed correlated with lifespan, but we found a significant interaction between pupal weight and sex on lifespan, and looking at the correlations we found that while the lifespan of males is positively correlated with pupal weight, female lifespan is not. It could be that females, rather than increasing lifespan, invest larval resources to maximize reproductive output as indicated by Kooi et al. [51]. Although in many species, including butterflies, larger body mass indeed leads to higher reproductive output of females [52-54], more direct evidence is clearly needed to substantiate this hypothesis.

4.4. Other Factors Influencing Sex-Specific Lifespan. It should be noted that other factors, which have not been investigated in this study, are also expected to influence sex-specific lifespan. Adult feeding can have important effects on sexspecific mortality rates and sexual behaviour (see also [55]). For example, Pararge aegeria (Satyridae) adults lived longer when fed [56] and in Pseudoplusia includens (Noctuidae), a shortage of food and water led to sex-specific lifespan in a population in which males normally live as long as females [57]. Furthermore, Gotthard et al. [56] found in the monandrous $P$. aegeria a difference in lifespan between males and females when females eclosed synchronously, but no difference when eclosion of females was continuous throughout the year (causing virgin females to be available over a longer period of time). Sex ratios in the field also play an important role because in a population of a monandrous species with more females than males, it is advantageous for a male to invest in lifespan as some virgin females will still be available after males have mated once. In monogamous species (in which male lifespan is expected to be shorter than female lifespan) with protandry (i.e., males eclose or become sexually active before females [58]), the earlier eclosion of males can reduce the difference in sex-specific lifespan. This is because male lifespan will tend to be increased to bridge the period between male and female eclosion. To test for male investment in lifespan in species with protandry, it is therefore better to determine if males continue to live after the peak of female receptivity, as we did in this study.

Our results supported the hypothesis of Wiklund et al. [25] that polyandrous males should invest in lifespan and therefore live about as long as females. The difference in polyandry between the species was however not reflected in male investment in lifespan. The data instead strongly suggest a large reduction of female lifespan by (as yet unknown) negative effects of mating. It would be interesting to elucidate the actual causes, that is, investigate the effects of multiple mating on male and female lifespan and discriminate between true costs of mating due to male manipulation and male-inflicted damage, and changes due to altered resource allocation after mating.

\section{Acknowledgments}

The authors thank Louis Lie and Wil van Ginkel for their help with rearing of the Yponomeuta moths and collecting data, and Emiel van Loon for statistical advice. They are grateful to Christer Wiklund and two anonymous reviewers for highly constructive comments on an earlier version of this paper.

\section{References}

[1] D. J. Hosken and P. Stockley, "Benefits of polyandry: a life history perspective," BMC Evolutionary Biology, vol. 33, pp. 173-194, 2003.

[2] R. Härdling and A. Kaitala, "The evolution of repeated mating under sexual conflict," Journal of Evolutionary Biology, vol. 18, no. 1, pp. 106-115, 2005.

[3] L. W. Simmons, "The evolution of polyandry: sperm competition, sperm selection, and offspring viability," Annual Review of Ecology, Evolution, and Systematics, vol. 36, pp. 125-146, 2005. 
[4] M. L. Taylor, C. Wigmore, D. J. Hodgson, N. Wedell, and D. J. Hosken, "Multiple mating increases female fitness in Drosophila simulans," Animal Behaviour, vol. 76, no. 3, pp. 963-970, 2008.

[5] F. Garcia-Gonzalez and L. W. Simmons, "Male-induced costs of mating for females compensated by offspring viability benefits in an insect," Journal of Evolutionary Biology, vol. 23, no. 10, pp. 2066-2075, 2010.

[6] E. H. Morrow, G. Arnqvist, and S. Pitnick, "Adaptation versus pleiotropy: why do males harm their mates?" Behavioral Ecology, vol. 14, no. 6, pp. 802-806, 2003.

[7] G. Arnqvist and T. Nilsson, "The evolution of polyandry: multiple mating and female fitness in insects," Animal Behaviour, vol. 60, no. 2, pp. 145-164, 2000.

[8] C. Cordero, "Chemical ornaments of semen," Journal of Theoretical Biology, vol. 192, no. 4, pp. 581-584, 1998.

[9] D. J. Kemp and R. L. Rutowski, "A survival cost to mating in a polyandrous butterfly, Colias eurytheme," Oikos, vol. 105, no. 1, pp. 65-70, 2004.

[10] T. Chapman, L. F. Liddle, J. M. Kalb, M. F. Wolfner, and L. Partridge, "Cost of mating in Drosophila melanogaster females is mediated by male accessory gland products," Nature, vol. 373, no. 6511, pp. 241-244, 1995.

[11] A. K. Das, J. Huignard, M. Barbier, and A. Quesneau-Thierry, "Isolation of the two paragonial substances deposited into the spermatophores of Acanthoscelides obtectus (Coleoptera, Bruchidae)," Experientia, vol. 36, no. 8, pp. 918-920, 1980.

[12] D. Gems and D. L. Riddle, "Longevity in Caenorhabditis elegans reduced by mating but not gamete production," Nature, vol. 379, no. 6567, pp. 723-725, 1996.

[13] E. H. Morrow and G. Arnqvist, "Costly traumatic insemination and a female counter-adaptation in bed bugs," Proceedings of the Royal Society B: Biological Sciences, vol. 270, no. 1531, pp. 2377-2381, 2003.

[14] H. S. Crudgington and M. T. Siva-Jothy, "Genital damage, kicking and early death," Nature, vol. 407, no. 6806, pp. 855856, 2000.

[15] W. U. Blanckenhorn, D. J. Hosken, O. Y. Martin, C. Reim, Y. Teuschl, and P. I. Ward, "The costs of copulating in the dung fly Sepsis cynipsea," Behavioral Ecology, vol. 13, no. 3, pp. 353358, 2002.

[16] T. Tregenza and N. Wedell, "Benefits of multiple mates in the cricket Gryllus bimaculatus," Evolution, vol. 52, no. 6, pp. 1726-1730, 1998.

[17] K. M. Fedorka and T. A. Mousseau, "Material and genetic benefits of female multiple mating and polyandry," Animal Behaviour, vol. 64, no. 3, pp. 361-367, 2002.

[18] M. Watanabe and K. Sato, "A spermatophore structured in the bursa copulatrix of the small white Pieris rapae (Lepidoptera, Pieridae) during copulation, and its sugar content," Journal of Research on the Lepidop-Tera, vol. 32, pp. 26-36, 1993.

[19] C. Wiklund, A. Kaitala, V. Lindfors, and J. Abenius, "Polyandry and its effect on female reproduction in the green-veined white butterfly (Pieris napi L.)," Behavioral Ecology and Sociobiology, vol. 33, no. 1, pp. 25-33, 1993.

[20] L. M. Torres-Vila, M. C. Rodríguez, and M. D. Jennions, "Polyandry and fecundity in the Lepidoptera: can methodological and conceptual approaches bias outcomes?" Behavioral Ecology and Sociobiology, vol. 55, no. 4, pp. 315-324, 2004.

[21] V. K. Iyengar and T. Eisner, "Female choice increases offspring fitness in an arctiid moth (Utetheisa ornatrix)," Proceedings of the National Academy of Sciences of the United States of America, vol. 96, no. 26, pp. 15013-15016, 1999.
[22] A. Bezzerides, T. H. Yong, J. Bezzerides et al., "Plant-derived pyrrolizidine alkaloid protects eggs of a moth (Utetheisa ornatrix) against a parasitoid wasp (Trichogramma ostriniae)," Proceedings of the National Academy of Sciences of the United States of America, vol. 101, no. 24, pp. 9029-9032, 2004.

[23] K. Ronkainen, A. Kaitala, and S. M. Kivela, "Polyandry, multiple mating, and female fitness in awater strider Aquarius paludum," Behavioral Ecology and Sociobiology, vol. 64, no. 4, pp. 657-664, 2010.

[24] A. González, C. Rossini, M. Eisner, and T. Eisner, "Sexually transmitted chemical defense in a moth (Utetheisa ornatrix)," Proceedings of the National Academy of Sciences of the United States of America, vol. 96, no. 10, pp. 5570-5574, 1999.

[25] C. Wiklund, K. Gotthard, and S. Nylin, "Mating system and the evolution of sex-specific mortality rates in two nymphalid butterflies," Proceedings of the Royal Society B: Biological Sciences, vol. 270, no. 1526, pp. 1823-1828, 2003.

[26] M. C. Birch, G. M. Poppy, and T. C. Baker, "Scents and eversible scent structures of male moths," Annual Review of Entomology, vol. 35, no. 1, pp. 25-58, 1990.

[27] Y. Tsubaki and K. Matsumoto, "Fluctuating asymmetry and male mating success in a sphragis-bearing butterfly Luehdorfia japonica (Lepidoptera: Papilionidae)," Journal of Insect Behavior, vol. 11, no. 4, pp. 571-582, 1998.

[28] M. J. Solensky, "The effect of behavior and ecology on male mating success in overwintering monarch butterflies (Danaus plexippus)," Journal of Insect Behavior, vol. 17, no. 6, pp. 723743,2004

[29] C. Wiklund, A. Kaitala, and N. Wedell, "Decoupling of reproductive rates and parental expenditure in a polyandrous butterfly," Behavioral Ecology, vol. 9, no. 1, pp. 20-25, 1998.

[30] A. J. Tamhankar, "Host influence on mating behavior and spermatophore reception correlated with reproductive output and longevity of female Earias insulana (Boisduval) (Lepidoptera: Noctuidae)," Journal of Insect Behavior, vol. 8, no. 4, pp. 499-511, 1995.

[31] N. Wedell, "Mate quality affects reproductive effort in a paternally investing species," American Naturalist, vol. 148, no. 6, pp. 1075-1088, 1996.

[32] C. E. Rogers and O. G. Marti Jr., "Once-mated beet armyworm (Lepidoptera: Noctuidae): effects of age at mating on fecundity, fertility, and longevity," Environmental Entomology, vol. 26, no. 3, pp. 585-590, 1997.

[33] B. Karlsson, "Nuptial gifts, resource budgets, and reproductive output in a polyandrous butterfly," Ecology, vol. 79, no. 8, pp. 2931-2940, 1998.

[34] H. Y. Fadamiro and T. C. Baker, "Reproductive performance and longevity of female European corn borer, Ostrinia nubilalis: effects of multiple mating, delay in mating, and adult feeding," Journal of Insect Physiology, vol. 45, no. 4, pp. 385392, 1999.

[35] M. G. E. Svensson, E. Marling, and J. Löfqvist, "Mating behavior and reproductive potential in the turnip moth Agrotis segetum (Lepidoptera: Noctuidae)," Journal of Insect Behavior, vol. 11, no. 3, pp. 343-359, 1998.

[36] P. A. Cook, "Sperm numbers and female fertility in the moth Plodia interpunctella (Hubner) (Lepidoptera; Pyralidae)," Journal of Insect Behavior, vol. 12, no. 6, pp. 767-779, 1999.

[37] C. W. Fox and C. M. Rauter, "Bet-hedging and the evolution of multiple mating," Evolutionary Ecology Research, vol. 5, no. 2, pp. 273-286, 2003. 
[38] A. Hendrikse, "Activity patterns and sex pheromone specificity as isolating mechanisms in eight species of Yponomeuta (Lepidoptera: Yponomeutidae)," Entomologia Experimentalis et Applicata, vol. 25, no. 2, pp. 172-180, 1979.

[39] A. C. Bakker, W. E. van Ginkel, P. Roessingh, and S. B. J. Menken, "Differences in mating strategies in two closely related small ermine moth species (Lepidoptera: Yponomeutidae)," European Journal of Entomology, vol. 105, no. 2, pp. 219-226, 2008.

[40] S. B. J. Menken, W. M. Herrebout, and J. T. Wiebes, "Small ermine moths (Yponomeuta): their host relations and evolution," Annual Review of Entomology, vol. 37, no. 1, pp. 41-66, 1992.

[41] H. Turner, N. Lieshout, W. E. Van Ginkel, and S. B. Menken, "Molecular phylogeny of the small ermine moth genus Yponomeuta (Lepidoptera, Yponomeutidae) in the palaearctic," PloS One, vol. 5, no. 3, Article ID e9933, 2010.

[42] R Development Core Team, R: A Language and Environment for Statistical Computing, R Foundation for Statistical Computing, Vienna, Austria, 2009.

[43] P. W. Walker and G. R. Allen, "Mating frequency and reproductive success in an income breeding moth, Mnesampela privata," Entomologia Experimentalis et Applicata, vol. 136, no. 3, pp. 290-300, 2010.

[44] R. A. Johnstone and L. Keller, "How males can gain by harming their mates: sexual conflict, seminal toxins, and the cost of mating," American Naturalist, vol. 156, no. 4, pp. 368 $377,2000$.

[45] A. C. Bakker, Mating strategies in small ermine moths, Ph.D. thesis, 2007.

[46] K. S. Oberhauser, "Male monarch butterfly spermatophore mass and mating strategies," Animal Behaviour, vol. 36, no. 5, pp. 1384-1388, 1988.

[47] K. S. Oberhauser, "Effects of spermatophores on male and female monarch butterfly reproductive success," Behavioral Ecology and Sociobiology, vol. 25, no. 4, pp. 237-246, 1989.

[48] C. Cordero, "Trade-off between fitness components in males of the polygynous butterfly Callophrys xami (Lycaenidae): the effect of multiple mating on longevity," Behavioral Ecology and Sociobiology, vol. 48, no. 6, pp. 458-462, 2000.

[49] D. M. O’Brien, C. L. Boggs, and M. L. Fogel, "Making eggs from nectar: the role of life history and dietary carbon turnover in butterfly reproductive resource allocation," Oikos, vol. 105, no. 2, pp. 279-291, 2004.

[50] R. H. Drent and S. Daan, "The prudent parent-energetic adjustments in avian breeding," Ardea, vol. 68, pp. 225-252, 1980.

[51] R. Kooi, W. M. Herrebout, and T. P. M Water, "Observations on pupal and imaginal weights of small ermine moths," Proceedings of the Koninklijke Nederlandse Akademie van Wetenschappen. Series C, vol. 92, pp. 81-88, 1989.

[52] L. Hughes, B. S. W. Chang, D. Wagner, and N. E. Pierce, "Effects of mating history on ejaculate size, fecundity, longevity, and copulation duration in the ant-tended lycaenid butterfly, Jalmenus evagoras," Behavioral Ecology and Sociobiology, vol. 47, no. 3, pp. 119-128, 2000.

[53] J. Bergström and C. Wiklund, "Effects of size and nuptial gifts on butterfly reproduction: can females compensate for a smaller size through male-derived nutrients?" Behavioral Ecology and Sociobiology, vol. 52, no. 4, pp. 296-302, 2002.

[54] C. L. Boggs and K. D. Freeman, "Larval food limitation in butterflies: effects on adult resource allocation and fitness," Oecologia, vol. 144, no. 3, pp. 353-361, 2005.
[55] N. I. Morehouse, T. Nakazawa, C. M. Booher, P. D. Jeyasingh, and M. D. Hall, "Sex in a material world: why the study of sexual reproduction and sex-specific traits should become more nutritionally-explicit," Oikos, vol. 119, no. 5, pp. 766778,2010 .

[56] K. Gotthard, S. Nylin, and C. Wiklund, "Mating opportunity and the evolution of sex-specific mortality rates in a butterfly," Oecologia, vol. 122, no. 1, pp. 36-43, 2000.

[57] R. L. Jensen, L. D. Newsom, and J. Gibbens, "The soybean looper: effects of adult nutrition on oviposition, mating frequency, and longevity," Journal of Economic Entomology, vol. 67, no. 4, pp. 467-470, 1974.

[58] J. Forsberg and C. Wiklund, "Protandry in the green-veined white butterfly, Pieris napi L. (Lepidoptera; Pieridae)," Functional Ecology, vol. 2, no. 1, pp. 81-88, 1988. 

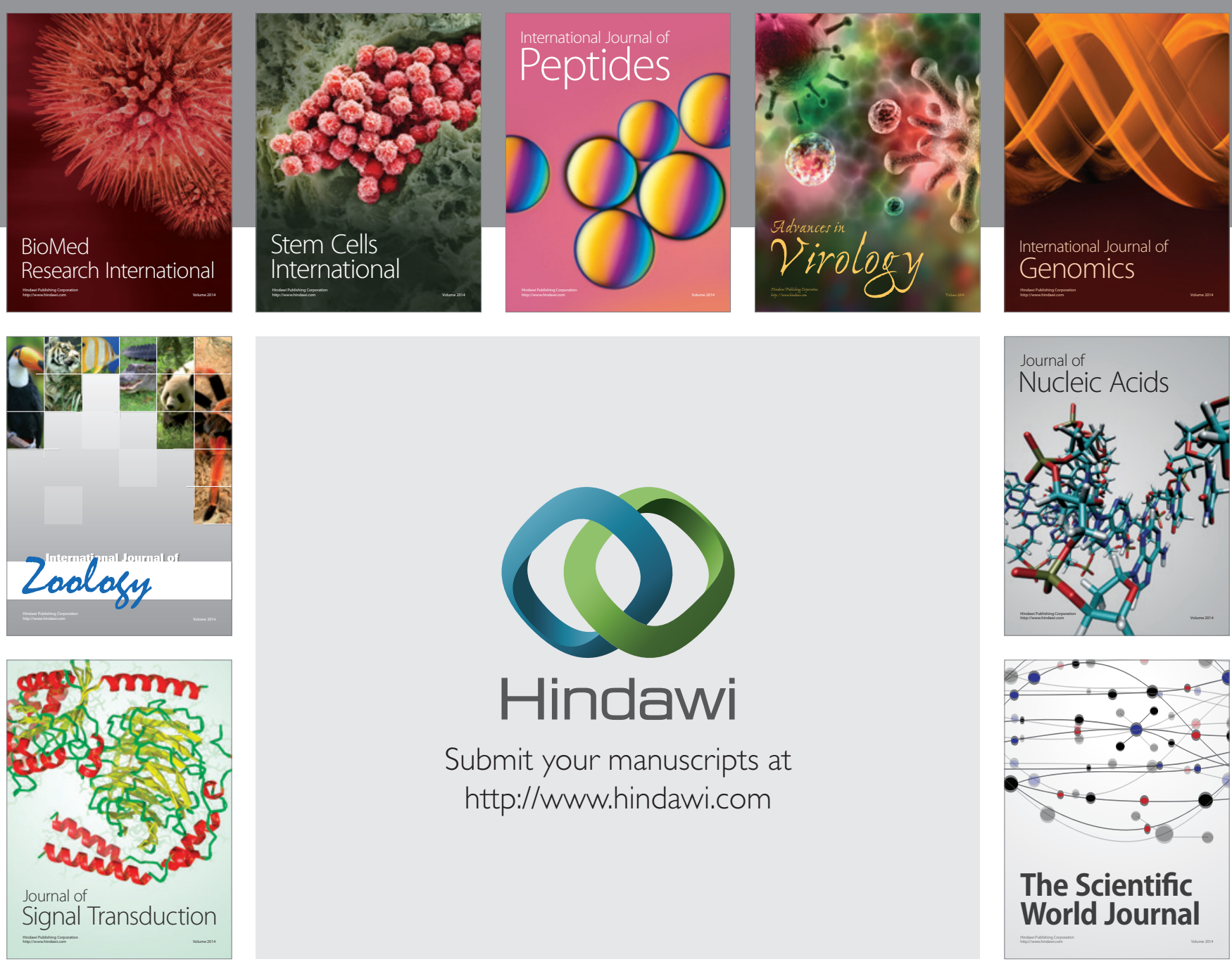

Submit your manuscripts at

http://www.hindawi.com
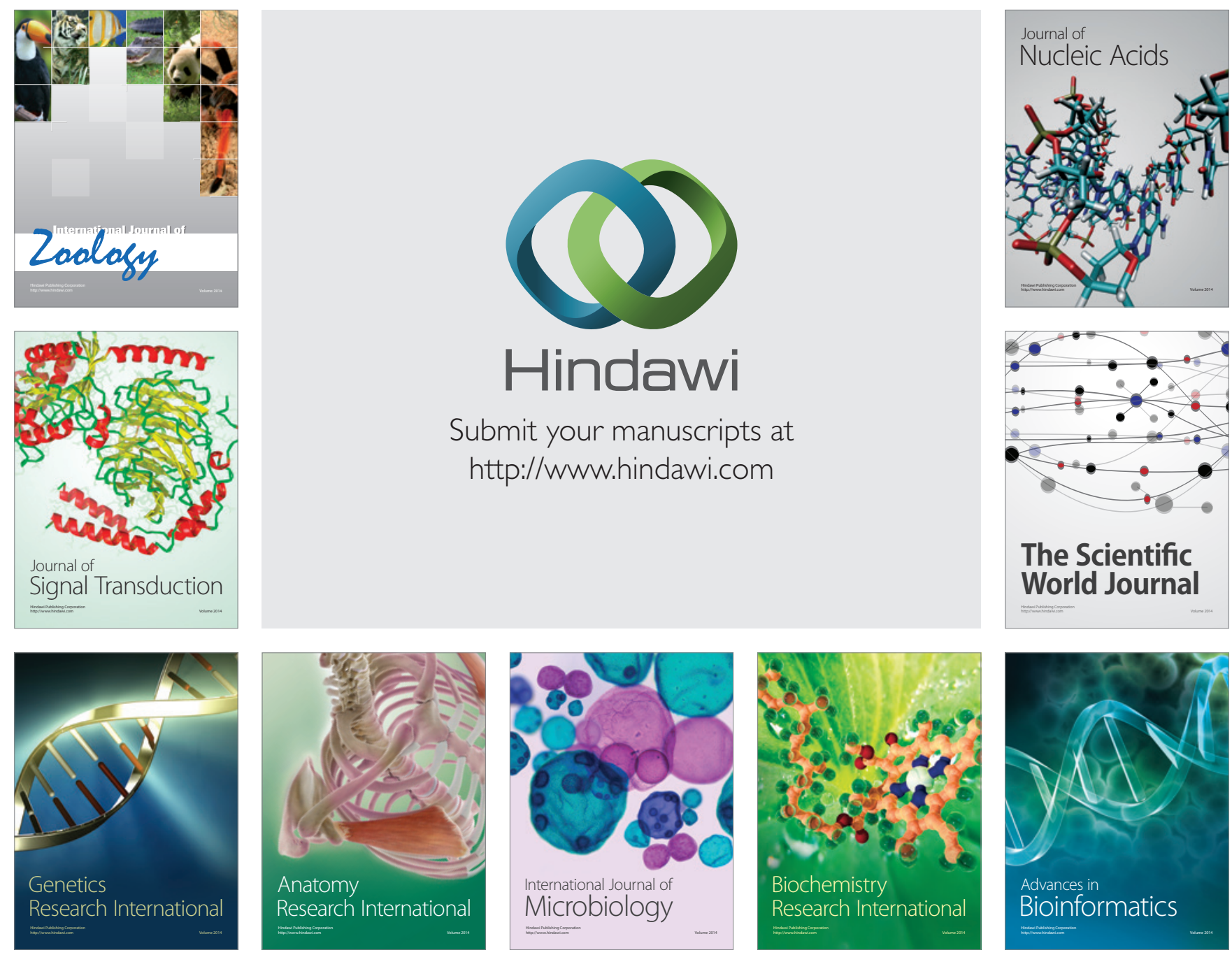

The Scientific World Journal
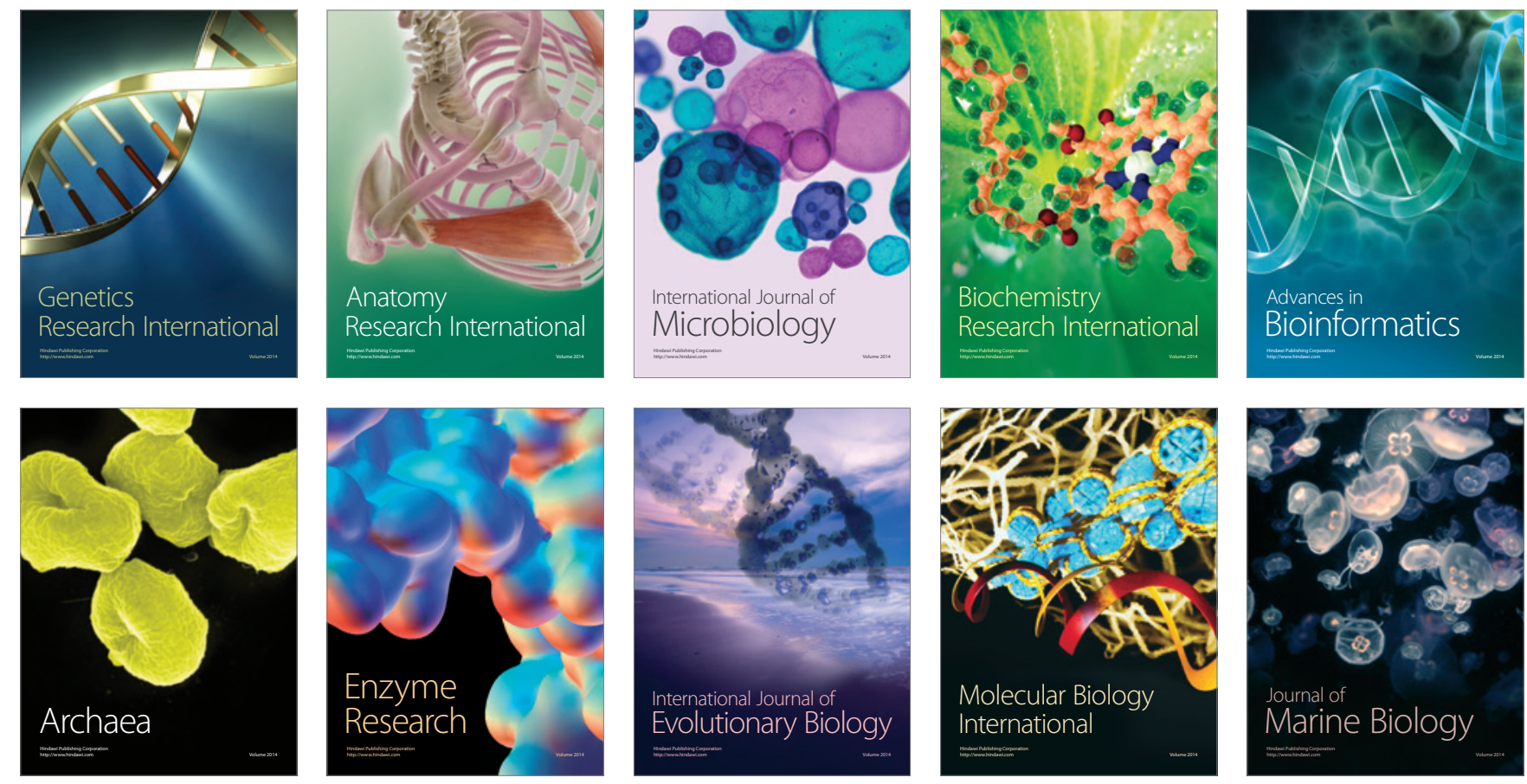